\title{
DETAILED STUDY OF BIFURCATIONS IN AN EPIDEMIC MODEL ON A DYNAMIC NETWORK
}

\author{
András Szabó, Péter L. Simon And Istvan Z. Kiss
}

\begin{abstract}
The bifurcations in a four-variable ODE model of an SIS type epidemic on an adaptive network are studied. The model describes the propagation of the epidemic on a network where links (or edges) of different type (i.e. SI,II and SS) can be activated or deleted according to a simple rule consisting of random link activation and deletion. In the case when II links cannot be neither deleted nor created it is proved that the system can have at most three steady states with the trivial, disease-free steady state being one of them. It is shown that a stable endemic steady state can appear through a transcritical bifurcation, or a stable and an unstable endemic steady state arise as a result of saddle-node bifurcation. Moreover, at the endemic steady state a Hopf bifurcation may occur giving rise to stable oscillation. The bifurcation curves in the parameter space are determined analytically using the parametric representation method. For certain parameter regimes or bifurcation types, analytical results based on the ODE model show good agreement when compared to results based on individual-based network simulations. When agreement between the two modelling approaches holds, the ODE-based model provides a faster and more reliable tool that can be used to explore full spectrum of model behaviour.
\end{abstract}

Mathematics subject classification (2010): 34C23, 37G10, 37N25, 92D30.

Keywords and phrases: fold, transcritical, Hopf bifurcations, adaptive network.

\section{REFERENCES}

[1] G. CsöRGő, P. L. Simon, Bifurcations in the differential equation model of a chemical reaction, Annales Univ. Sci. Budapest., 53 (2010), 45-57.

[2] H. FARKAS, P. L. SIMON, Use of the parametric representation method in revealing the root structure and Hopf bifurcation, J. Math. Chem., 9 (1992), 323-339.

[3] W. Govaerts, J. Guckenheimer, A. Khibnik, Defining functions for multiple Hopf bifurcations, SIAM J. Numer. Anal., 34 (1997), 1269-1288.

[4] T. Gross, C. J. Dlima Dommar, B. Blasius, Epidemic dynamics on an adaptive network, Phys. Rev. Lett., 96 208701, 2006.

[5] T. Gross, B. Blasius, Adaptive coevolutionary networks: a review, J. Roy. Soc. Interface, 5 (2008), 259-271.

[6] T. House, M. J. KeELING, Insights from unifying modern approximations to infections on networks, J. Roy. Soc. Interface, 8 (2010), 67-73.

[7] M. J. KeELing, The effects of local spatial structure on epidemiological invasions, Proc. R. Soc. Lond. B, 266 (1999), 859-867.

[8] B. NAgY, Analysis of the Biological Clock of Neurospora, J. Comp. Appl. Math., 226 (2009), 298305.

[9] S. Ris AU-Gusman, D. H. ZANETTE, Contact switching as a control startegy for epidemic outbreaks, J. Theor. Biol., 257 (2009), 52-60. 
[10] J. SARAMÄKI, K. KASKI, Modelling development of epidemics with dynamic small-world networks, J. Theor. Biol., 234 (2005), 413-421.

[11] L. B. Shaw, I. B. Schwartz, Fluctuating epidemics on adaptive networks, Phys. Rev. E, 77, 066101, 2008.

[12] P. L. Simon, H. Farkas, M. WitTmann, Constructing global bifurcation diagrams by the parametric representation method, J. Comp. Appl. Math., 108 (1999), 157-176.

[13] P. L. SimON, E. HILD, H. FARKAS, Relationships between the discriminant curve and other bifurcation diagrams, J. Math. Chem., 29 (2001), 245-265.

[14] M. Taylor, P. L. Simon, D. M. Green, T. House, I. Z. Kiss, From Markovian to pairwise epidemic models and the performance of moment closure approximations, J. Math. Biol., DOI: 10.1007/ s00285-011-0443-3.

[15] I. Z. Kiss, L. BERTHOUZE, T. J. TAYLOR, P. L. Simon, Modelling approaches for simple dynamic networks and applications to disease transmission models, submitted to Proc. R. Soc. A. 